\title{
BMJ
}

\section{Concept of unbearable suffering in context of ungranted requests for euthanasia: qualitative interviews with patients and physicians}

\author{
H R W Pasman, senior researcher, ${ }^{1}$ M L Rurup, senior researcher, ${ }^{1}$ D L Willems, professor, ${ }^{2}$ B D Onwuteaka- \\ Philipsen, associate professor ${ }^{1}$
}

VU University Medical Center, EMGO Institute for Health and Care Research, Department of Public and Occupational Health, Expertise Center for Palliative Care, van der Boechorststraat 7, $1081 \mathrm{BT}$, Amsterdam, Netherlands

${ }^{2}$ Academic Medical Center/ University of Amsterdam Department of General Practice, Meibergdreef 15, $1105 \mathrm{AZ}$

Amsterdam

Correspondence to: H R W Pasman hrw.pasman@vumc.nl

Cite this as: BMJ 2009;339:b4362 doi:10.1136/bmj.b4362

\section{ABSTRACT}

Objective To obtain in-depth information about the views of patients and physicians on suffering in patients who requested euthanasia in whom the request was not granted or granted but not performed.

Design In-depth interviews with a topic list.

Setting Patients' homes and physicians' offices.

Participants 10 patients who explicitly requested euthanasia but whose request was not granted or performed and eight physicians of these patients; and eight physicians of patients who had requested euthanasia but had died before the request had been granted or performed or had died after the request was refused by the physician or after the patient had withdrawn his or her request.

Results Not all patients who requested euthanasia thought their suffering was unbearable, although they had a lasting wish to die. Patients and physicians seemed to agree about this. In cases in which patients said they suffered unbearably there was less agreement about what constitutes unbearable suffering; patients put more emphasis on psychosocial suffering, such as dependence and deterioration, whereas physicians referred more often to physical suffering. In some cases the physician thought that the suffering was not unbearable because the patient's behaviour seemed incompatible with unbearable suffering-for instance, because the patient was still reading books.

Conclusions Patients do not always think that their suffering is unbearable, even if they have a lasting wish to die. Physicians seem to have a narrower perspective on unbearable suffering than patients and than case law suggests. In an attempt to solve the problem of different perspectives, physicians should take into account the different aspects of suffering as described in the literature and a framework for assessing the suffering of patients who ask for euthanasia.

\section{INTRODUCTION}

In 2005 , about 8400 people in the Netherlands made an explicit request for euthanasia. Of these, about 2400 requests were granted, and euthanasia was performed. ${ }^{1}$ In the other cases, several situations can arise: the patient dies after the request is granted but before euthanasia is performed (13\% of all requests), the patient dies before the physician has made the final decision to grant or to refuse the request (13\%), the patient withdraws his or her request (13\%), or the physician refuses $(12 \%) .{ }^{2}$ Most of the requests are made to general practitioners (77\% of all requests in 2005). ${ }^{1}$

The Dutch Euthanasia Act (2002) describes six requirements for due care in the performance of euthanasia. ${ }^{3}$ If the requirements are met and euthanasia is performed, the physician will not be prosecuted. One of the requirements is that the physician must be convinced that the patient's suffering is unbearable, with no prospect of improvement. Unbearable suffering is not further specified in the act, but the views of the Royal Dutch Medical Association, ${ }^{4}$ the regional euthanasia review committees, ${ }^{3}$ and case law ${ }^{5}$ provide some indications: unbearable suffering is not limited to physical suffering, the suffering must at least be recognisably unbearable for the physician, and unbearable suffering is subjective. It is crucial to consider the patient's personal judgment in the assessment of unbearable suffering.

The first and third aspect correspond with Cassell's concept of suffering. ${ }^{6}$ He defined suffering as the state of severe distress associated with challenges that threaten the intactness of the person. Thus, suffering is experienced by an individual and occurs when an impending damage of the person is perceived by that individual. This damage, or loss, can occur in different aspects of personhood, such as the person's history, his or her cultural and societal attachments, the roles of the person, a person's perceived or desired future, and the spiritual life of the person. According to Cassell, the only way to know whether suffering is present is to ask the person. One reason why physicians misunderstand the nature of suffering is medicine's traditional mind-body dichotomy. In this dichotomy, suffering can either be related to the mind, in which case it is regarded as subjective and not truly "real" and possibly placed outside the domain of medicine or it can be seen as primarily related to the body and, from there, as exclusively related to bodily pain. ${ }^{6}$ 
The Dutch euthanasia law requires that physicians, as attending physician or consultant, assess the patient's suffering and whether it is unbearable. Acknowledging Cassell's concept of suffering and the importance of looking at the whole person, both mind and body, a framework was designed for the training in formal consultation in the context of euthanasia requests in the Netherlands. ${ }^{7}$ This framework consists of different aspects of suffering: one part of the description is empirical, focusing on observable items and descriptions of personality, biography, and environment; the other part is the hermeneutic aspect, focusing on what each of these aspects means to a patient and how each aspect contributes to unbearability.

In view of the above described complexity of the concept of suffering, it is not surprising that the most debated requirement for due care is that the physician has to be convinced that the suffering of the patient is unbearable. Physicians say it is the most difficult requirement to form a judgment on. ${ }^{1}$ Doubts about the presence of unbearable suffering are also the most frequently mentioned reason given by physicians for refusing a request or feeling reluctant to grant a request. $^{28}$ Anecdotal evidence shows that patients whose request for euthanasia is refused feel that the physician did not understand their suffering. ${ }^{9} \mathrm{We}$ explored how patients who requested euthanasia and physicians describe and understand the patient's suffering. Better understanding of this can help the discussion about the extent to which professional and judicial concepts of unbearable suffering apply in practice. We examined how patients whose request for euthanasia was not granted or performed described their suffering and how their physicians assessed suffering in those specific cases, and how they describe unbearable suffering in general.

\section{METHODS}

Recruitment and sampling

We recruited patients from a large cohort study focusing on people with advance directives (that is, advance euthanasia directive, refusal of treatment document, durable power of attorney for health care, will to live statement). In this study, about 5000 people with one or more advance directives received a written questionnaire every 18 months. In the baseline written questionnaire of this study in 2005 we asked whether the respondent had made a request for euthanasia in the past three years and the reason why the request was not granted (that is, the request was refused by the physician or request was withdrawn by respondent). Furthermore, we asked whether the respondent had had a relative who had requested euthanasia that had not been granted or performed, and then asked why the request had not been granted or performed (for instance, patient died before euthanasia, patient died before the final decision, request had been refused by physician after which the patient had died from another cause, or request had been withdrawn by patient after which the patient had died from another cause). In total there were 51 respondents who had requested euthanasia in the past three years but the physician had refused, one respondent had withdrawn his request, and 135 respondents had known a relative who had requested euthanasia but euthanasia was not performed.

We selected respondents for the present interview study on the basis of these two questions, combined with data on sex and the health status of the respondent (terminal illness, chronic illness, no physical illness) because we expected differences in (degree of) suffering in patient with different illnesses. We were interested in cases in which euthanasia was not performed as we know that doubts about the degree of suffering are often mentioned as the reason for physicians to refuse a request. ${ }^{28} \mathrm{We}$ also included cases with different reasons why the request was not granted or performed as we expected that perspectives on suffering could vary according to the reason for not granting or performing euthanasia.

\section{Interviews}

We interviewed 10 patients, eight of whom gave us consent to approach their physician (one patient had two physicians to whom she had addressed a request for euthanasia), and we interviewed eight of the nine physicians of these patients (one physician refused because of lack of time). We also interviewed eight physicians about seven different patients who had asked for euthanasia but had died before the request had been granted or performed or had died after the request was refused by the physician or after the patient had withdrawn his request. We recruited these eight physicians through respondents in the cohort study who had stated that their relative had requested euthanasia but that the request had not been granted or granted but not performed.

The interviews took place from December 2005 to September 2007. We interviewed the patients in their home for 60-120 minutes and the physicians in their office for 30-60 minutes.

We used interview topic lists based on the objectives of the study. Lists for both the patients and the physicians included the current situation of the patient, including suffering, the situation of the patient at the time of the request, reasons for asking euthanasia, and reasons why euthanasia was not granted or performed. Patients and physicians were asked not only to describe the suffering in their specific case but also how they would describe unbearable suffering in general. We started the interviews with patients with a general question about their current situation and their request for euthanasia. We started the interviews with physicians with a general question about the patient's request. Further questions were based on what the respondents said. At the end of the interview the researcher checked whether all topics had been covered. ${ }^{10}$

\section{Data analysis}

We analysed data from the interviews with the 10 patients and the 16 physicians, covering 17 different 


\begin{tabular}{|c|c|c|c|}
\hline Case & Patients' characteristics & Interviewees & Reason that euthanasia was not performed* \\
\hline 1 & Man aged $<50$, cancer (glandular cell) (died) & General practitioner & Died before euthanasia \\
\hline 2 & Woman aged >80, cancer (pancreas) (died) & General practitioner & Died before euthanasia \\
\hline 3 & Man aged 71-80, cancer (lung), (died) & General practitioner & Died before final decision \\
\hline 4 & Man aged $<50$, Crohn's disease & Patient, internist & Request refused/request refused \\
\hline 5 & Woman aged $>80$, paralysed after stroke & $\begin{array}{l}\text { Patient, current nursing home physician, } \\
\text { former nursing home physician }\end{array}$ & Request refused/request refused, request refused \\
\hline 6 & Woman aged 61-70, Alzheimer's disease (deceased) & Nursing home physician, geriatrician & Request refused/request refused \\
\hline 7 & Woman aged >80, Alzheimer's disease (died) & Nursing home physician & Request refused \\
\hline 8 & Woman aged $>80$, rheumatism & Patient, general practitioner & Request refused/request refused \\
\hline 9 & $\begin{array}{l}\text { Man aged } 61-70, \text { several strokes, Parkinson's disease, } \\
\text { depressive symptoms }\end{array}$ & Patient, general practitioner & Request refused/request refused \\
\hline 10 & Man aged ı80, Parkinson's disease, severe constipation (died) & General practitioner & Request refused \\
\hline 11 & $\begin{array}{l}\text { Woman aged }>80 \text {, colon cancer, rheumatism, asthma, heart } \\
\text { failure, Menière's disease }\end{array}$ & Patient (no consent to interview physician) & Request refused/unknown \\
\hline 12 & Woman aged $>80$, stroke, neurological problems & Patient (physician refused because of lack of time) & Request refused/unknown \\
\hline 13 & Man aged $>80$, stroke, depressive symptoms & Patient, general practitioner & Request refused/request refused \\
\hline 14 & Man aged $>80$, Parkinson's disease & Patient, general practitioner & Request refused/request refused \\
\hline 15 & Woman aged $>80$, heart failure & Patient, (no consent to interview physician) & Request refused/unknown \\
\hline 16 & Man aged 61-70, cancer (prostate) (died) & General practitioner & Request withdrawn \\
\hline 17 & Woman aged $>80$, weak sighted & Patient, general practitioner & No explicit request/no explicit request \\
\hline
\end{tabular}

*From perspective of interviewees.

cases. All interviews were recorded and fully transcribed. As our study was explorative, not theoretical, we used open, not axial or selective coding, as described by Strauss and Corbin. ${ }^{11}$ We read the transcripts of the interviews several times and categorised them into similar subject areas using inductive coding. Examples of codes are degree of suffering, nature of suffering (physical and non-physical), relation to daily activities or behaviour, and relation to a patient's biography. Two researchers (HRWP and BOP) carried out this coding process and generated the list of codes that was discussed with the other researchers. In the course of the sequential analysis, ${ }^{11}$ we noticed similarities between our results and Cassell's concept of suffering. We started to use Cassell's concept as an analytical framework, and, in the further analyses, we focused on whether suffering was related to body, mind, or the whole person (and to which aspects of the person). Our preliminary findings were discussed with the research advisory committee, which included practising physicians with experience in dealing with requests for euthanasia.

\section{RESULTS}

\section{Characteristics of patients and physicians}

The patients had various diseases and illnesses, most of them were aged over 80 , and half of them were women (table).

Of the 16 physicians interviewed, 10 were general practitioners, four were nursing home physicians, one was a geriatrician, and one was an internist (table). All physicians had at least five years of working experience and had received requests for euthanasia in the past. Most of them had also performed euthanasia in the past. One physician was not willing to perform euthanasia for religious reasons.

\section{Considering suffering to be unbearable}

Some patients explicitly stated that their suffering was unbearable, while others said that they did suffer unbearably but not all the time or said that their suffering was severe but questioned whether it was unbearable. Whether or not patients considered their suffering to be unbearable, they all had a lasting death wish. The physicians also did not call all suffering unbearable, and the perspectives of the patient and the physician were similar in most of the cases in which both perspectives had been described.

Coherence, as considered by the physician, seemed to play an important role in assessing the severity of the suffering. In some cases the physician thought that the suffering was not unbearable because the patient behaved in a way that the physician did not think was compatible with unbearable suffering. For instance, one physician said that the patient was still reading books and therefore seemed not to be suffering unbearably. However, the patient said about her reason for reading: "But it's only that I try to fill in the time, by what I call 'eating up letters'.” Another physician stated that the patient was still able to ride a bicycle, which he saw as incompatible with a serious wish to die. A third physician said that the patient still managed to live more or less independently, while the patient said that he carried on with his life for his family. "You'd rather stay in bed, but then you think I can't do that because there are visitors coming, or there's help coming, or I have to do something, so come on lazy bones, get up ... I make myself do that for others."

\section{Is unbearable suffering physical suffering?}

Most of the patients mentioned pain as an element of their suffering, but this was not the only cause, and the pain did not make their suffering unbearable. For the 
Box 1: Unbearable suffering; patients' perspective

\section{Case 5 (woman aged $\mathbf{8 0}$, paralysed after stroke)}

Interviewer (I): And now they say that patients must meet a few requirements, and one important requirement is unbearable suffering-you already mentioned that yourself. What do you think unbearable suffering is?

Respondent (R): That you are alive, but not living. They call it living, because you're breathing, but l'm not living. You can't call this living, can you?

I: And what does living mean to you then?

R: Being part of everyday life. For instance, if I can read, see a play ...

Case 8 (woman aged $\mathbf{8 0}$, rheumatism)

R: Sometimes I think, why do I want to die? But nobody needs me, and I think that's what it is. It's not only the pain, I'm just not needed. And I . . I'm so unhappy at night.

Case 9 (man aged 61-70, several strokes, Parkinson's disease, depressive symptoms) R: No, my pain isn't unbearable. I sometimes have pain in my back, and then at other times it's somewhere else. And all sorts of problems with my body-awful trouble with my bowels, for instance, and pain in my neck-I do have that so I go to a physiotherapist who massages my neck. That does help a bit.

I: But it's not unbearable?

R: No, I wouldn't even call that unbearable, no.

I: But your whole situation?

R: I find it really horrible. But not unbearable, because I go on living every day, and each day comes and goes. Tomorrow is another day.

Case 12 (woman aged $\mathbf{8 0}$, stroke, neurological problems)

I: And can you explain why you want it [euthanasia]?

R: Well, because soon I shall need help with everything, and that's not much of a life. That's not worthwhile-sitting down all day, and I don't want to go to see my children any more, it's all so difficult, isn't it? If you go to get the post, then you slouch across the floor, and after that you have to be in a wheelchair, which you never get out of again, so what's the use of it all?

Case 14 (man aged >80, Parkinson's disease)

R: Mentally it's unbearable for me, it's mentally unbearable that I bloody well have to get worse than I am already and worse than I used to be.

patients themselves, the suffering seemed to mainly consist of non-physical suffering, such as (fear of) dependence, no longer being able to participate in normal daily life, or mental suffering because of deterioration (box 1).

For the physicians, physical suffering and, in particular, (severe) pain seemed to be a more important element of suffering. In cases in which the physician thought that the patient's suffering was unbearable (see the first quote in box 2), the physicians described the suffering as severe pain and chronic fatigue. Moreover, in their description of unbearable suffering in general, about half of the interviewed physicians mentioned physical suffering or said that it is easier to define the suffering as unbearable if it is physical (box 2).

\section{Empathising with the patient's suffering is not enough}

Most of the physicians could understand that their patient wanted to die. Some physicians said that they would, perhaps, also have wanted to die if they were in a similar situation. For most of the physicians, however, empathy with or understanding of the death wish was not enough to persuade them to grant the request for euthanasia (box 3 ).

\section{Is unbearable suffering subjective?}

Several patients thought that certain situations (such as having a stoma or becoming dependent) would be unacceptable and therefore unbearable for them, whereas similar situations might well be acceptable for other patients. Some of the physicians also thought that unbearable suffering is subjective: what is bearable for one patient can be unbearable for another patient. Some physicians, however, thought otherwise (box 4).

\section{DISCUSSION}

Patients who request euthanasia do not always consider their suffering as unbearable, and patients and physicians seem to agree about this. If the patients say they suffer unbearably, however, there is less agreement between patients and physicians about what constitutes unbearable suffering. The patients evoke several aspects of personhood when they speak about their suffering. They put more emphasis on psychosocial suffering, such as dependence, deterioration, and not being able to participate in life anymore, whereas the physicians refer more often to physical suffering. Moreover, some physicians compare the situation of a patient who requests euthanasia with that of other patients in similar situations.

\section{Strengths and weaknesses of the study}

We looked at unbearable suffering from different perspectives. Previous studies have asked physicians about the suffering of their patients who requested euthanasia. ${ }^{12812}$ One limitation of our study is that we looked only at cases in which a request for euthanasia had not been granted or granted but not performed (about two thirds of all requests), and the perspectives of patients and physicians with regard to unbearable suffering might be different in cases where euthanasia was performed-for instance, showing more agreement between patients and physicians. We do not think that the source of selection of respondents (people with an advance directive) caused selection bias as most people who request euthanasia (around 93\%) have an advance euthanasia directive. ${ }^{112}$

\section{Nature of suffering}

When patients describe unbearable suffering they look at various aspects of personhood, and physical suffering is not the main factor. Physicians in our study, however, defined unbearable suffering more often as physical suffering. This confirms Cassell's notion that, in medicine, suffering is generally related to the body and not to the mind. ${ }^{6}$ In the context of euthanasia, the difference can also be influenced by the different interests of patients and physicians: patients want euthanasia and physicians want certainty about the legal aspects. It is possible that physicians therefore use a rather strict definition of unbearable suffering as being physical suffering. Furthermore, physical 
Box 2: Unbearable suffering; physicians' perspective

\section{General practitioner (woman aged 40-50)}

Interviewer( $(I)$ : And unbearable, what does that mean?

Respondent (R): Well, pain. He just had so much pain in his ribs and around his liver, yes and in his bones, because it had spread to the bones in his back. And he had a morphine pump, but yes, that Friday I think it was that I wrote out the request for the drugs used in euthanasia.

\section{General practitioner (woman aged 440 )}

I: Have you, yourself, any idea about what unbearable suffering is?

R: Lots of pain, difficult to treat, so much trouble with the medicine, side effects, that people really do suffer, yes suffer, have pain, are tired, can't function any more, and also, can't do certain things any more, that they lie there crying, they lie in bed moaning.

\section{General practitioner (man aged $>50$ )}

I: Do I understand well that for you, unbearable suffering is not necessarily associated with physical suffering?

R: Somatic no, certainly not. But it must be-the problem is that it also has something to do with my own powerlessness. Of course you prefer the somatic symptoms just because they're more apparent, and of course there can be much more discussion about the psychological aspect.

\section{General practitioner (man aged $>50$ )}

R: Yes, unbearable suffering is in any case the type of suffering, yes, when you think that somebody has a lot of pain, who has been treated with all possible pain medication, who is in a hopeless situation in terms of the disease and everything that she (the patient) is going through. It's not hopeless. Yes, OK, she's in her eighties and yes, life has to end sometime, but hopeless in terms of wanting to end it all, I can imagine that from someone with terminal cancer.

suffering is probably the most apparent and recognisable suffering, and physicians might be most familiar with this physical domain. This difference in perspective can be problematic for patients who request euthanasia as it is a requirement that the physician must at least recognise that the suffering is unbearable for the patient.

\section{Box 3: Empathising with the patient's suffering is not enough}

\section{General practitioner (woman aged 440 )}

Interviewer (I): Can you empathise?

Respondent (R): Yes, I can. Yes. But I don't usually find that difficult. Yes, I also understand it. Perhaps when I'm as old as she is, then I shall also think: "Oh well, that's enough". But yes, that's not what it's like in reality.

\section{General practitioner (man aged 40-50)}

R: For him it's unbearable, and I totally agree with him. I've had long talks with him about it - know that it's unbearable for him, but, yes.

I: And then they say that suffering is subjective. The doctor must know that the patient finds it unbearable and must at least feel empathy to go along with it.

R: Well yes, but that's a bit of a problem for me.

\section{General practitioner (man aged 40-50)}

R: I mean, if I knew that I could no longer see and I came into a different setting where I had no idea where anything was, I mean, I realise very well, I really can understand that this is what she wants. But you see, in my work I experience so many situations in which the agony and the suffering are evident. But that doesn't mean that my role in these cases is that I end their life ... Empathy is not always enough-however difficult it is, because it's certainly not easy.
Outside of the euthanasia context, Baines and Norlander $^{13}$ indicated from their study among 92 patients in a hospice that these patients viewed pain and suffering as separate entities. More patients experienced suffering than pain. Patients suffered, for instance, because of loss of enjoyment of life or concerns for loved ones. Although we asked the physicians in our study how they defined unbearable suffering in general, we asked it within an interview about euthanasia. It is not clear how these physicians would describe suffering outside of the context of euthanasia, but when this is similar and primarily seen as physical suffering, patients' non-physical suffering in general might not be recognised or underestimated and consequently might be undertreated.

\section{Suffering is subjective}

In legal euthanasia proceedings, unbearable suffering is considered to be subjective, thus tied to a subject's experience of suffering. This gives physicians the opportunity to take the personhood of the patient, such as their personal history, into consideration in their assessment of unbearable suffering. Some of the physicians in this study stated that this indeed was part of their assessment, but others did not take personhood into account; they compared the situation of the patient with that of other patients in comparable situations and could then come to the conclusion that the suffering should not be unbearable for their patient. The latter does not seem to comply with Cassell's notion that the only way to find out whether someone suffers (and, we would add, the degree to which they suffer) is to ask the patient. ${ }^{6}$ Physicians also do not seem to comply with this notion when they expect congruence between behaviour and suffering as expressed by the patient.

Is unbearable suffering an applicable term in the assessment of euthanasia requests?

Some patients themselves had doubts about whether or not their suffering was unbearable or stated that their suffering was not unbearable all the time. And yet, these patients considered their suffering to be severe and clearly indicated that they had a lasting wish to die. This gives rise to the following question: how can patients, on the one hand, consider their suffering to be so severe that they no longer wish to live, but, on the other hand, not consider it to be unbearable? It is possible that patients reserve the term "unbearable" for the most extreme situations and find it unreasonable to consider their own suffering in this way.

\section{Conclusions and implications for practice}

Patients and physicians have different perspectives on the nature and extent of suffering. Physicians commonly focus on bodily suffering and seem to have a narrower perspective on unbearable suffering than patients and than Dutch case law suggests. ${ }^{5}$ Physicians should take into account the various aspects of suffering, looking beyond the body-mind dichotomy. The 
Box 4: Is unbearable suffering subjective?

\section{Case 4 (man aged <50, Crohn's disease)}

Respondent (R): I don't want a stoma. No way! I'd rather you got rid of me. A bag of shit on my stomach, I've lived for so many years in a degrading situation. These are degrading situations you lie in. You just lie there, because there was a hole in it, wallowing in your own shit in the bed. Isn't that lovely! And then you also have to walk around with a bag of shit on your stomach! Don't be silly, I'm not that type. I've been through such hell already. I still have a certain feeling of self esteem, that I can't accept it, I just don't want it. Even if thousands of people say 'I'm feeling better with it, I don't mind at all, it doesn't bother me, I can swim with it, I can do this and that with it." OK, good for them!

\section{Physician of case 4 (man aged 40-50)}

Interviewer (I): The point he makes-about a stoma being the last straw, can you empathise with that?

R: No, I find it difficult to understand. I mean, there are patients with a stoma who have improved enormously. Of course they had a different illness profile, yes, but there are those who are really happy with it, no more pain, able to eat normally, no longer constantly feeling rotten. Those people are much better off.

\section{General practitioner (woman aged 40-50)}

I: What do you understand by unbearable suffering?

R: Well, that's a whole range of what people... It often has to do with how people have lived and what their condition is now. So that can range from you don't have any pain but you're lying in bed and you have to poo and wee in a nappy and you can't do anything else. I could certainly consider that to be unbearable suffering without any pain involved. So it very much depends on how your life has been and what you find unbearable.

\section{General practitioner (man aged >50)}

I: Do you yourself have a definition or an idea about what unbearable suffering is?

R: Yes, but then you base it mainly on yourself, don't you, that what you think is unbearable at this moment. But I think that it could also differ, now that I'm 55 or when I'm 75 , or, for instance when I'm not ill or when I am ill. I think that they are definitely sliding scales, and I also think that the only person who can decide is the patient. And if the patient can communicate this to the doctor, then I think that the doctor really ought to go along with it. But it's enormous - what are the circumstances, and what can you bear and what can't you bear.

\section{General practitioner (man aged 40-50)}

I: It is in any case, from what I understood from him, a considerable contrast with his situation before the Parkinson's.

R: Yes, but yes, that applies to every Parkinson's patient and to every stroke patient. Do we have to grant all their requests for euthanasia? No, I'm not doing that.

framework mentioned in the introduction could help physicians to achieve this. It will help them to assess suffering in the context of requests for euthanasia in a structured way, taking into account all possible aspects of suffering, and thus reduce the gap between the

\section{WHAT IS ALREADY KNOWN ON THIS TOPIC}

Unbearable suffering is the most debated requirement for euthanasia and is experienced by physicians as the most difficult to determine

More than half of the explicit requests for euthanasia in the Netherlands are not granted or are granted but not performed

\section{WHAT THIS STUDY ADDS}

Not all patients who want to die consider their suffering to be unbearable

Patients and physicians have different perspectives on what constitutes unbearable suffering

To assess the severity of a patient's suffering, physicians could use a framework specifying different aspects of suffering patients' and physicians' perspective of suffering. Furthermore, it can structure a conversation between the patient and physician about the suffering of the patient.

A consequence of using a broad perspective of suffering could be that physicians more often assess the suffering of a patient as unbearable. The opposite is also possible, and, taking all aspects of suffering into account, physicians could less often conclude that the suffering is unbearable for that person. In any case, with a structured way of assessing suffering the assessment will at least be more in line with the nature of suffering, more systematic, and open for discussion and evaluation. This is not only useful in discussing requests for euthanasia but also in end of life care in general.

We thank all the patients and physicians who shared their experiences and opinions with us. Their contribution to the research is invaluable. We also thank G K Kimsma for his comments on the manuscript. Contributors: BDO-P had the initial idea for this study and wrote the research proposal. HRWP and MLR undertook the interviews. HRWP and BDO-P did the coding and analyses, which was discussed with MLR and DLW. HRWP wrote the first draft. BDO-P, MLR, and DLW commented on and contributed to the final draft. BDO-P is guarantor. All contributors had access to all the data and can take responsibility for the integrity of the data and the accuracy of the data analysis

Funding: This study was supported by a grant from Right to Die-NL

(NVVE) and the Pieter van Foreest Foundation. The funders approved the study design and were not involved in the collection, analysis, and interpretation of data, the writing of the report, and the decision to submit the article for publication. The researchers were independent from the funders

Competing interests: None declared.

Ethical approval: The study protocol was approved by the Medical Ethics Committee of the VU University medical center (METC VUmc registration No 2005/82)

Data sharing: No additional data available.

1 Onwuteaka-Philipsen BD, Gevers JKM, van der Heide A, et al. Evaluation of the law of review of ending of life on request and assisted suicide. ZonMw, 2007. [In Dutch.]

2 Jansen-van der Weide MC, Onwuteaka-Philipsen BD, van der Wal G. Granted, undecided, withdrawn, and refused requests for euthanasia and physician-assisted suicide. Arch Intern Med 2005;165:1698-704.

3 Regional euthanasia review committees: annual report. 2007 www. euthanasiecommissie.nl/Images/Jaarverslag\%202007\%20Engelse \%20versie tcm21-11566.pdf

4 Vision on Euthanasia. Board of the Royal Dutch Medical Association, 2003. [In Dutch.]

5 Explanatory memorandum 'Termination of Life on Request and Assisted Suicide (Review Procedures Act.') [In Dutch: Memorie van toelichting bij het westvoorstel 'Wet levensbeeindiging op verzoek en hulp bii zelfdoding.'] Kamerstukken II 1998-1999, 26 691, № 3.

6 Cassell EJ. The nature of suffering and the goals of medicine. N EnglJ Med 1982;306:639-45.

7 Kimsma GK. The assessment of suffering. A proposal for a conceptual framework. [Het lijden beoordeeld. Een voorstel voor een conceptueel kader]. Medisch Contact 2000;55:1757-9. [In Dutch.]

8 Haverkate I, Onwuteaka-Philipsen BD, van der heide A, Kostense P. van der Wal G, van der Maas PJ. Refused and granted requests for euthanasia and assisted suicide in the Netherlands: interview study with structured questionnaire. BMJ 2000;321:865-6.

9 Van Dam H. Euthanasia. A different look at practice. Interviews with relatives. [Euthanasie. De praktijk anders bekeken. Interviews met nabestaanden.] Uitgeverij Libra \& Libris, Veghel, 2005. [In Dutch.]

10 Britten N. Qualitative research: qualitative interviews in medical research. BMJ 1995;311:251-3.

11 Strauss A, Corbin J. Basics of qualitative research. Sage, 1990.

12 Onwuteaka-Philipsen BD, Heide A. van der, Koper D, et al.Euthanasia and other end-of-life decisions in The Netherlands in 1990, 1995 and 2001. Lancet 2003;362:395-9.

13 Baines BK, Norlander L. The relationship of pain and suffering in a hospice population. Am J Hospice Palliat Care 2000;17:319-26.

Accepted: 17 July 2009 